\title{
Comparability of Biologics: Global Principles, Evidentiary Consistency and Unrealized Reliance
}

\author{
Christopher J. Webster ${ }^{1} \cdot$ Kelly L. George ${ }^{2}$ - Gillian R. Woollett ${ }^{2}(\mathbb{0}$
}

Accepted: 27 May 2021 / Published online: 18 June 2021

(c) The Author(s) 2021

\begin{abstract}
The principles of comparability assessments have been accepted globally as offering sensitive and reliable tools with which to evaluate potential changes to biologics that may arise either through processing changes or through the creation of a copy (biosimilar) by a different sponsor. The comparability approach has evolved through systematic advances in four areas: clear and convergent guidelines for evaluation of potential changes to biologics; risk-based systems of weighting analytical data; progressive improvements in analytical methods; and advanced understanding of post-translational modifications. Routine regulatory expectations for clinical equivalence data are being reevaluated, as they seldom contribute to the assessment of similarity. Similarly, we show that requirements to compare biosimilars and locally sourced versions of their reference products are of questionable scientific value and represent a double standard by comparison with the invariable acceptance of the clinical profiles of novel biologics without reference to their sources. The consistent application of evidentiary standards for comparability to all biologics offers an opportunity for regulators to curtail their own assessments of new biosimilars and instead to recognize comparability assessments made in another jurisdiction (reliance), thereby gaining important efficiencies in the regulatory review of biosimilars and improving the competitiveness of the biosimilars market. Such consistency can also enhance the confidence of all stakeholders, especially patients and their providers, in all biologics.
\end{abstract}

\section{Comparability: A Global Standard Approach}

The purpose of the assessment of the comparability of two versions of a biologic is to determine that the efficacy and safety (clinical properties) of the versions are not meaningfully different despite a known difference between their manufacturing provenances. If, after investigation, it is concluded that the versions are analytically similar and have essentially indistinguishable clinical properties, they are said to be comparable [1]. The need for this assessment arises either when a change has been made to the manufacturing process of the drug or when a different sponsor has made a presumptive copy (biosimilar) of an existing biologic.

Although these applications of comparability are operationally different [1-4], they share a critical reliance upon the certainty that function follows form. Given that biologics are often structurally heterogeneous $[5,6]$, a product's

Gillian R. Woollett

gwoollett@avalere.com

BioApprovals, Acton, MA, USA

2 Avalere Health, Washington, DC, USA

\section{Key Points}

Comparability of biologics is a validated technical approach in routine use by sponsors and regulators worldwide.

Comparability assessments are enabled by systematic advances in four areas: clear and convergent guidelines for evaluation of potential changes to biologics; riskbased systems of weighting analytical data; progressive improvements in analytical methods; and advanced understanding of glycosylation and other post-translational modifications.

Regulators have not applied consistent evidentiary standards of comparability to the licensure of innovators' biologics and biosimilars in new markets.

When a reference product has been approved in multiple markets, supported in each by some of the same clinical data, only a single full evaluation of biosimilarity is usually necessary, and the biosimilar is approvable in other markets by reliance upon the first evaluation. 
functional properties are variable within a range of values representing the proportional contributions from each of the structural subpopulations contained therein. Information available prior to formal comparability studies (e.g., the identical upstream precursors and processing, in the case of manufacturing changes; the purposeful design of the expression construct to yield a protein with the same primary amino acid sequence as the reference product, in the case of a biosimilar) already supports the expectation that the versions are analytically and functionally alike, which confirms the appropriateness of a comparability approach. The objective of the comparability assessment is to demonstrate that the pre- and post-change products are sufficiently alike that their clinical properties will be indistinguishable, and, like pregnancy, comparability is a binary condition. In assessments following manufacturing changes to a product, analytical data (including data from in vitro functional studies) are almost invariably considered to be sufficient by all major regulators; only rarely is there a need to conduct studies in humans. ${ }^{1}$. The robustness and reliability of the comparability approach is demonstrated by the fact that most biologics undergo many comparability assessments of this type, which enable the efficient management of their life cycles $[8,23]$. As discussed later, for biosimilars, limited clinical studies in either human volunteers or patients are necessary to complete the evidentiary basis for regulatory action. This basis has been termed the "confirmation of sufficient likeness" [7].

While regulatory convergence implies that independent regulators are applying similar scientific standards and decision frameworks to reach similar conclusions independently, regulatory reliance means that independent regulators, rather than performing assessments themselves, are relying to a significant extent upon the assessment and conclusions of another regulator to determine the regulatory acceptability of a given product. In this paper, we review the origins of comparability and its convergent application to enable the efficient development and life cycle management of all biologics as well as the rapid and low-cost propagation of biosimilars. We point out potential improvements to be made and argue that it is time to apply consistent evidentiary standards for comparability to all biologics. Consistent application of the science of comparability would improve the efficiency of biologics regulation and could enable the

\footnotetext{
${ }^{1}$ Dr. Janet Woodcock, Deputy Commissioner and Chief Medical Officer, US FDA, testified before the US Congress House Committee on Oversight and Government Reform on 'Follow-on Protein Products', March 26, 2007 (testimony at https://www.fda.gov/NewsEvents/ Testimony/ucm 154070.htm). During the question-and-answer session, Dr Woodcock stated that, in the FDA's experience, when biologics sponsors use a comparability approach to justify manufacturing changes to biologics, clinical data are required in not more than 1-2\% of cases, if that.
}

use of regulatory reliance to enhance access to these critical therapies [14].

\section{Origins of Comparability}

The theoretical and practical approach to comparability as a regulatory process was pioneered by the US FDA in the late 1980 s and early 1990 s to deal with manufacturing changes to the first emergent biologics produced by recombinant biotechnology. The FDA summarized these approaches in its comparability guidance of April 1996 [15]. In a concept paper [16] published in June 1998, the Biologicals Working Party of the European Medicines Agency (EMA) Committee for Proprietary Medicinal Products (CPMP) noted the FDA's initiative in its comparability guidance of 1996 but also emphasized that this guidance was silent on the issues pertaining to the comparison of versions of biologics from different manufacturers. The CPMP proposed to create its own guidelines to cover assessments of comparability of biotechnology-derived proteins both after manufacturing changes and when products originated from different manufacturers (biosimilars). This initiative produced two guidelines $[17,18]$ that described both of these situations and established the regulatory foundations for the approval of biosimilars. Under the auspices of the International Council for Harmonization, the principles identified by both the FDA and the EMA were synthesized in a common guideline [1], which is now implemented by all major regulators to assess manufacturing process changes to biologics produced by recombinant technology. Implementation of the principles identified for the evaluation of biosimilars resulted in the approval of the first biosimilar (human growth hormone; Omnitrope ${ }^{\mathrm{TM}}$, Sandoz) in the EU in 2006.

The advent of biosimilars in the USA was delayed by the lack of an appropriate pathway under existing law, but this deficiency was eventually overcome by the passage of the Biologics Price Competition and Innovation Act of 2009 as Title VII of the Patient Protection and Affordable Care Act of 2010. Guidances for biosimilar development issued subsequently by the FDA were influenced heavily by those already published by the EMA, as were the guidelines issued in other jurisdictions and by the World Health Organization (WHO) [19-22]. Although there are differences of detail between the data requirements for registration of biosimilars in different global jurisdictions (e.g., requirements for local clinical studies), they clearly have a single origin. Moreover, as we discuss in the following, some regulatory differences are not scientifically justified and could be removed without negative consequences for either patients or sponsors of biologics. Indeed, they would result in the same product ultimately being approved. 


\section{Evolution of Analytical Characterization}

Analytical testing has always been the foundation of comparability $[1,17]$. In the early years of comparability, required analytical tests were largely limited to demonstrations that products manufactured after a process change complied with pre-change specifications. However, as the types of changes that manufacturers wished to validate through comparability grew wider in scope, and particularly with the advent of biosimilars, the required analytical data became more extensive, to include, for example, analyses of post-translational modifications (PTMs) and of multiple product batches [17]. Critically, there have been systematic advances in four areas.

a. Clear and technically convergent guidelines have been published by major regulators as to their expectations for analytical data to be included in successful comparability assessments $[1,17,38]$. The guidelines emphasize the use of panels of sensitive and orthogonal analytical techniques, in which the data from different methods confirm and amplify each other (e.g., data from mass spectrometry methods confirm and amplify data from chromatographic methods, and vice versa). The application of these guidelines creates a powerful but flexible evidentiary process that is the foundation for all comparability assessments and is often sufficient to confirm comparability without the use of other methods.

b. Risk-based systems of weighting analytical data have been developed [25-27], attributing the weights according to the relevance of the data to the clinical properties of the product. Wider variances between the pre- and post-change products (or between reference and biosimilar) are more acceptable for lower-weighted data than for highly weighted data; for the most highly weighted data (e.g., primary protein structure), no variance between the pre- and post-change product versions is permitted and identicality is required, with some specific exceptions (e.g., removal of C-terminal lysines). Risk-based thinking about the development of biosimilars also allows a more flexible, less rigid or legalistic approach to regulation, allowing improvements in efficiency by maintaining a focus on variables that truly impact quality, and de-emphasizing those that do not [28].

c. Progressive improvements in in vitro analytical methods to assess composition and function, and innovation of analytical technologies, have allowed sponsors to characterize and compare biologics with ever more efficiency, sensitivity and precision [29-33]. These improvements have increased the confidence of sponsors and regulators in the relevance and validity of analytical comparability assessments and removed the necessity for comparisons of biological activity by studies in animals $[7,55]$. d. Understanding of glycosylation and other PTMs to proteins, and their impact and control, has greatly improved $[24,34]$ so that biologic developers can now take a proactive approach to the design of new glycosylated biologics and their manufacturing processes, even to the extent of "engineering" desired glycoforms [35]. This is of particular importance because the pharmacokinetics and many of the vital biological functions of biologics are impacted critically by the extent and nature of their PTMs. Moreover, adventitious differences in glycoforms and other PTMs are prolific causes of batch variation in manufactured biologics and functional differences between biosimilar candidates and their reference products $[36,37]$. Given that the maintenance of a consistent functional profile for each biologic is of paramount importance as both a regulatory and a clinical matter, an adequate specification for the glycosylation of each biologic is desirable, and this specification should be confirmed for each batch of drug substance and product, unless an exception is justified. This would remove the possibility for there to be significant excursions of glycosylation across multiple batches that go undetected and uncorrected, as has occurred [36].

These approaches, applied together, have allowed comparability assessments to become extremely sensitive and reliable tools for the evaluation of product changes [10] provided that they are applied in a carefully planned and structured way to anticipate potential sources of inaccuracy or error [38].

\section{Requirements for Clinical Data}

Clinical data are seldom required for the regulatory acceptance of manufacturing changes to biologics. ${ }^{2}$ This is because these changes have generally been shown to have had no or limited effects upon the analytical variables of the postchange version. Assuming that both versions (pre-change and post-change) of the product have had the same processing upstream of the change, and analytical variables of the post-change version have remained within their specified ranges, it has been concluded that the functionality of the post-change version will not have changed. When the change made has been more profound or likely to have caused unspecified analytical changes that may be associated with differences of functionality (e.g., change of expression system), the post-change product is usually not accepted as continuous and is re-categorized as, for example, a line extension or a new product.

\footnotetext{
${ }^{2}$ See footnote 1.
} 
For biosimilars, guidance has also been given on the nonclinical and clinical data that may be expected to characterize structurally related families of products [39-41]. Data from comparative human pharmacokinetic and immunogenicity studies are required for the approval of biosimilars in highly regulated jurisdictions $[2,9]$. These data supplement the data obtained from analytical studies, which are not informative as to the distribution in vivo or the immunogenicity of a product that has a different provenance from its reference. While pharmacokinetics are not a proxy for clinical efficacy, they provide a sensitive method to show that the dispositions of a biosimilar and its reference, which are primary functional components of efficacy, are similar over the duration of the study. A pharmacokinetic study can usually be designed as the single clinical study to support the efficiency of a biosimilar development program if a comparative evaluation of the immunogenicities of the biosimilar and its reference are integrated within it [7, 13]. Pharmacokinetics are usually studied after the administration of a single dose of drug to naïve participants, but the collection of immunogenicity data requires repeated dosing at intervals, with monitoring of pharmacokinetics and antidrug antibodies after each dose. The study also provides an opportunity to evaluate the comparative safety profile of the biosimilar.

The standard adopted by most regulators for the assessment of the pharmacokinetic similarity of biosimilars is that, using an average equivalence statistical approach, a $90 \%$ confidence interval for the ratio between the geometric means of the parameters of the proposed biosimilar product and the reference product should lie between 80 and $125 \%$ [42, 43]. Other limits may be proposed but should be justified. These limits did not originate from studies of biologics but from equivalence studies with small-molecule drugs, and experience with biosimilars indicates that most lie within substantially closer limits to their references [45]. However, the pharmacokinetics of several comparisons have fallen outside the acceptance limits, but, rather than preventing approval of the product, this has usually been attributed to some cause of inaccuracy and the data either accepted or the study re-run [44-46]. Despite their use, it is unknown whether these generic drug limits are optimal for the characterization of biologics. In principle, this is undesirable; the relationship of acceptance criteria to concrete quality endpoints should always be known.

For biosimilars, regulators have also required specific evidence that the pharmacodynamic profile of a biosimilar conforms to that of its reference. If the molecule has a suitable pharmacodynamic biomarker (e.g., insulins, filgrastims), a comparative pharmacodynamic study in a relevant population is ideal. Most biosimilars do not have such biomarkers (nor are they available for the reference biologics) so, in these cases, a powered clinical equivalence study has been expected instead. However, after the approval of around 100 biosimilars in highly regulated jurisdictions, in no case has a biosimilar that was found to be highly similar to its reference in analytical and pharmacokinetic studies failed to meet its endpoint in a clinical equivalence study $[7,44]$. These findings provide compelling evidence that analytical and pharmacokinetic data showing similarity together routinely fulfill the condition for comparability stated in the Q5E guideline [1] that "the existing knowledge is sufficiently predictive to ensure that any differences in quality attributes have no adverse impact upon safety or efficacy of the drug product." In these circumstances, equivalence studies generally do not provide new information as regards biosimilarity, which is their purported justification. As a consequence, the UK's regulator was recently the first to announce revisions of its requirements for clinical equivalence data and may no longer require them routinely for the approval of biosimilars [11, 12]. Other regulators are considering similar adjustments [13]. These changes are driven partly by the typical redundancy of clinical equivalence trials to the conclusion of biosimilarity and the lack of ethical justification for unnecessary trials $[7,47]$ but also enable significant savings of resources and time in the development of new biosimilars for no change in the product finally approved [7, 10].

\section{Consistency of Evidentiary Standards and Interoperability of Comparability Data}

The common history and design of comparability assessments in every major jurisdiction has the consequence that these assessments reflect a globally shared process, essentially a lingua franca, which enables the global "interoperability" of the data. This can greatly facilitate regulatory reviews, allowing extensions of marketing authority and significant savings of cost, labor and time [28]. It also means that the biologics used as reference products for biosimilars are comparable across multiple jurisdictions as changes in manufacturing are routinely applied to all markets, and variations remain within acceptable ranges [23].

While biosimilars are required to be analytically highly similar to their references, the endpoint of a comparability assessment is defined not as whether a qualitative difference is present but whether a difference in the clinical properties of the product has been introduced [1]. This definition applies not only to the comparison of a biosimilar and its reference but also to comparisons of reference product versions sourced from different jurisdictions. For novel biologics, regulators require that the investigational product that is used by an originator in pivotal (phase III) clinical studies is fully representative of the product that will be marketed subsequently $[48,49]$ in the territory under their 
jurisdiction. As such, the data from these studies set the clinical profile of the product for all time, unless its composition is changed intentionally, whereupon new studies are normally necessary. Sponsors of biologics almost invariably support their products' indications in multiple jurisdictions by submission of the same clinical data, some of which are reproduced in the product label or official monograph, which are binding public documents. The necessary implication of the licensure of the product in multiple jurisdictions upon the same clinical data is that the product versions marketed in each jurisdiction are, in fact, comparable to each other [50], and this is justified by the confidence that regulators have in the reliability of the comparability approach to serial manufacturing changes $[8,23]$. While it is possible to demonstrate minor qualitative differences between different local versions, and between each local version and the version used in pivotal studies, there is no doubt that regulators have accepted that these differences are of no consequence for comparability. As a practical matter, therefore, the reference product is recognized as the same everywhere [23, 50]. If this were not the case, regulators would need to require new clinical studies for each indication of the reference versions from each source.

The consequence of this conclusion is that there is no scientific basis for differentiation between versions of a reference product from different jurisdictions in the evaluation of a biosimilar because reference product versions are already known to be comparable to each other-this is why biosimilars are routinely found to be biosimilar to each local version of their references. Regulatory requirements to show analytical similarity of a biosimilar to local versions of the reference product in different jurisdictions [2] (at (1) in Fig. 1), or to demonstrate a "bridge" between a local version of the reference and a version sourced elsewhere and used as the comparator in studies to establish biosimilarity [9], are unnecessary and tedious impositions upon biosimilar sponsors to generate data whose conclusions are already known [50]. They also represent an unjustified double standard (shown at A in Fig. 1) by reference to the universal regulatory practice in the homologous situation with innovators' biologics, in which the same clinical data are accepted to support approvals of reference products in multiple jurisdictions, despite those local versions not being shown to be comparable with the version used in the original phase III studies that established the clinical profile of the product (at (2) in Fig. 1). The comparability of these different versions of the reference to each other is simply assumed on the basis of manufacturing conformity rather than assessed formally and de novo in each case. In reality, regulators can accept biosimilarity data generated against any authentic version of the reference, irrespective of its source, if a biosimilar sponsor has substantiated that the same clinical data ${ }^{3}$ have been adduced to support approval of the reference in both jurisdictions (i.e., the jurisdiction from which the reference version has been sourced and the jurisdiction in which approval of the biosimilar is to be sought). This is a relevant standard because first, the clinical properties of compared biologics are defined as the endpoint of a comparability assessment and second, the clinical data published for a reference biologic are inherently linked to its formulation. Biosimilar sponsors can substantiate this relationship by showing that the same clinical data appear in the product labels from both jurisdictions. As shown in Fig. 1, this acceptance by regulators would represent the application of the same calculus to biosimilars as has been applied to reference biologics for decades and would greatly facilitate the development of new biosimilars with no loss of scientific rigor or safety and no change in the product that is finally approved. It is notable that the same biosimilar licensed in two jurisdictions has confirmed the validity of these assumptions for subsequent biosimilars to that same reference product.

\section{Regulatory Reliance as the Pathway to Efficiency of Biosimilar Development}

Moreover, because it is necessary for the evaluation of a biosimilar to be conducted only once when the references in different jurisdictions are comparable, an important efficiency for a vigorous marketplace for biosimilars lies in jurisdictions relying upon the scientific assessments of other competent regulators in authorizing the distribution of biosimilars in their own territories. Reliance is a precedented solution that offers important advantages for regulators [14] and is a particularly rational approach for biosimilars, as it offers a means to avoid the need to source reference product from more than one jurisdiction, a means to address potential absences of specific technical skills, a means to lighten heavy workloads and a means to shorten reviews of biosimilars. While independent reviews of novel therapies by each jurisdiction are necessary to provide for local differences in medical practice and in evaluations of risk and benefit, these considerations do not apply to biosimilars. Regulators are already closely familiar with the drug from their experience with the reference product marketed in their territories and evaluate biosimilars based on that experience. Moreover, the orthogonal and replicate nature of biosimilarity

\footnotetext{
${ }^{3}$ Logically, it is not necessary that all the clinical data in common between versions of the reference are the same. As a guarantee of comparability, it is sufficient that some of the clinical data (say, supporting a single indication) are the same for versions of the reference across the jurisdictions.
} 


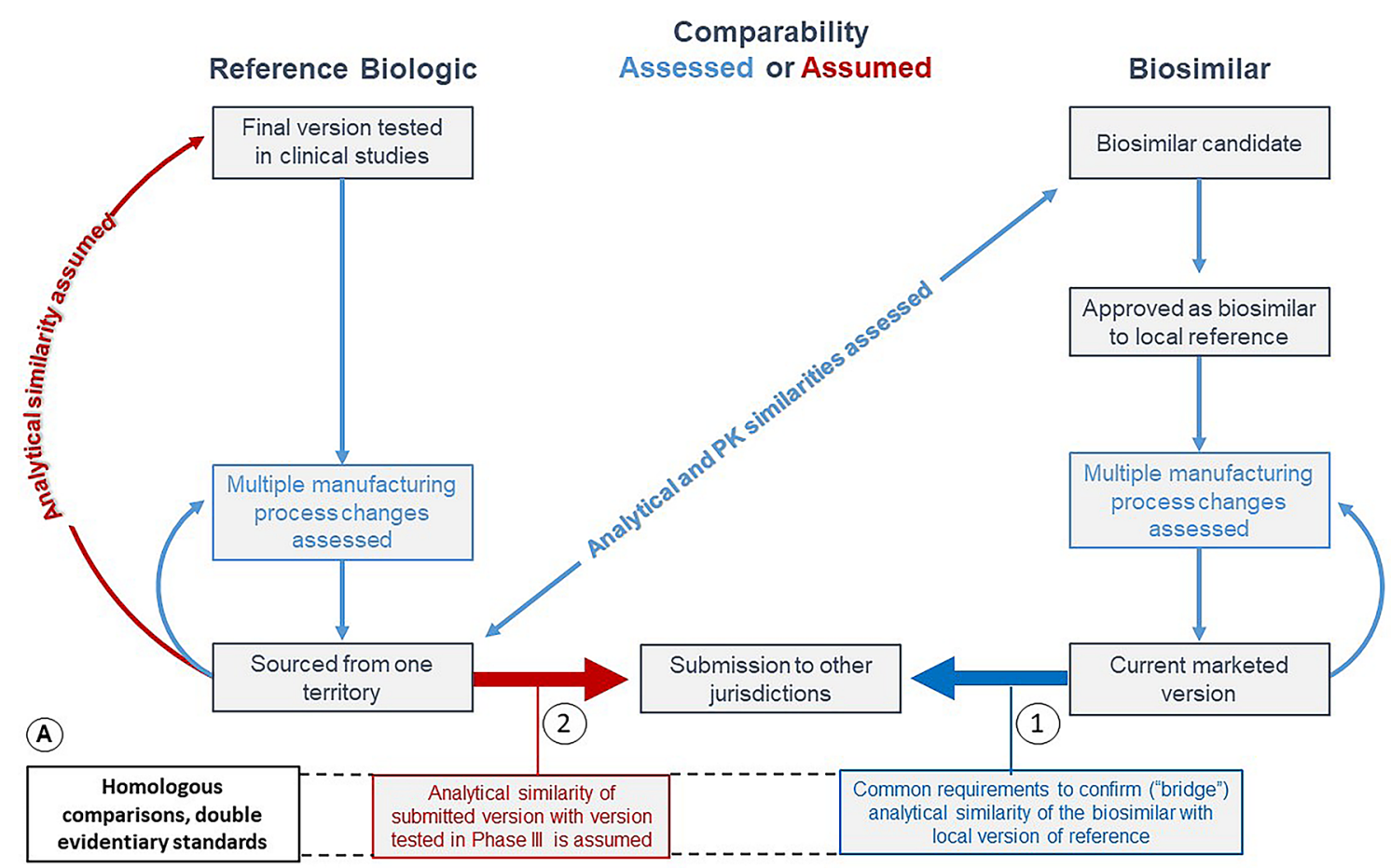

Fig. 1 Assessed and assumed comparabilities for reference biologics and biosimilars. The figure shows the different evidentiary standards applied, without scientific basis, to reference products and biosimilars in geographic extensions

data ensures that conclusions are unequivocal and not liable to differ between competent reviewers. Iterative de novo reviews of the same data by different regulators, entailing the cumulative expenditure of thousands of hours of regulatory authority resources, lengthening of review times and disproportionate amounts of money in additional comparisons of reference product versions, user fees and other regulatory expenses, are unnecessary and grossly wasteful when such a simple and efficient alternative is readily available.

A simple means of regulatory reliance would be the provision, by regulators in a highly regulated jurisdiction in which a biosimilar were to be licensed first, of a comprehensive official assessment report, such as the European Public Assessment Reports prepared by the EMA or the discipline review reports prepared by the review divisions of the FDA and certification to document the fact that the product had been approved based on a full comparability assessment, including appropriate clinical studies, as biosimilar to a named reference, with the identifier(s) of the original pivotal study(ies) of the reference indicated (e.g., sponsor's study numbers or identifiers in a public database, e.g., clinicaltrials.gov). There would not necessarily be any formal agreements between participating regulators outside of any agreements required by the reliance scheme. The certificate would be available upon request to biosimilar sponsors by means of a process similar to the current processes for issuance of, for example, a Certificate of Free Sale or a Certificate of Pharmaceutical Product.

Because of the criticality of the phase III clinical studies conducted with the reference product to the setting of the clinical properties of the reference described in its product label or monograph, and the inherent link of these clinical properties to the reference product formulation to which the biosimilar must be found comparable, the regulators issuing certificates should also list in the certificate the identifiers of the clinical studies conducted with the reference products licensed in their jurisdictions. Any regulator wishing to evaluate the biosimilar by reliance could thus ensure that the reference product to which the biosimilar had been found similar was comparable to the reference product licensed in their own jurisdiction, by determining that the clinical data submitted for the reference product in both jurisdictions were the same. (Rarely, the formulations of a reference product licensed in different jurisdictions, perhaps even under the same name, may not be the same but the clinical properties of the formulations would typically be investigated in different studies.)

Biosimilars with this certification could be accepted as comparable to the local version of the reference product in a new market without further examination if that reference were seen to be supported by clinical data from studies identified in the certificate [23, 50]. Reliance upon a technical assessment conducted in another jurisdiction would 
not subsequently commit regulators to the same, or indeed any, regulatory action, and they would retain their statutory independence and responsibilities for regulation at all times. We appreciate that this form of reliance would have similarities to the pilot program established by the WHO for prequalification of biosimilars [51], but major differences would be that, under this scheme, the products would have been reviewed and authorized formally by a statutory regulator $^{4}$ and the process would be easily available to any biologic rather than restricted to the limited number ${ }^{5}$ available under the WHO scheme.

Regulators wishing to use a reliance process for approvals of biosimilars would probably require sponsors to submit a product dossier with their marketing applications, which would enable the submission of any confidential information that was redacted from the review reports prepared by regulators conducting the primary reviews. The dossiers would also be required by regulators to manage the life cycle maintenance of the biosimilar after its approval. Clearly, the submission of the product dossier with the marketing application would not oblige the regulator to conduct a full review; its approval decision could be based upon reliance, with its inherent advantages as detailed earlier.

\section{Conclusion}

Biosimilars allow patients access to biological therapies that have often been transformative of the standard of care but to which, without biosimilars, access would be limited or delayed on grounds of cost [7]. Further, biosimilars have been shown to be a critical tool for the control of national healthcare costs [52-54], at least in developed countries. Quality biosimilar products and rigorous evaluation are both required and are enabled by the careful application of the science of comparability, a versatile and globally accepted approach. A critical lever for the improvement of access and control of healthcare costs is the efficiency of development and review because such improvements in efficiency can allow more competition in the marketplace. Given its practical simplicity, regulatory reliance would be an important contributor to improvement of this efficiency.

Acknowledgements The authors are grateful to Hillel Cohen, Martin Schiestl, Arnold Vulto, and Anna Rose Welch for helpful review and commentary.

\footnotetext{
4 The WHO prequalification scheme for biosimilars expressly does not commit to this condition.

${ }^{5}$ Currently, only trastuzumab and rituximab.
}

\section{Declarations}

Funding No sources of funding were used to conduct this study or prepare this manuscript.

Conflicts of interest Christopher J. Webster, Kelly L. George, and Gillian R. Woollett have no conflicts of interest that are directly relevant to the content of this article.

Ethics approval Not applicable

Availability of data and material All data and materials were sourced from the public domain.

Consent Not applicable.

Author contributions KLG-literature research, graphics; GRW-concept discussion, text editing, proofing; $\mathrm{CJW}$ - concept discussion, text writing, editing.

Open Access This article is licensed under a Creative Commons Attribution-NonCommercial 4.0 International License, which permits any non-commercial use, sharing, adaptation, distribution and reproduction in any medium or format, as long as you give appropriate credit to the original author(s) and the source, provide a link to the Creative Commons licence, and indicate if changes were made. The images or other third party material in this article are included in the article's Creative Commons licence, unless indicated otherwise in a credit line to the material. If material is not included in the article's Creative Commons licence and your intended use is not permitted by statutory regulation or exceeds the permitted use, you will need to obtain permission directly from the copyright holder. To view a copy of this licence, visit http://creativecommons.org/licenses/by-nc/4.0/.

\section{References}

1. International Council for Harmonisation of Technical Requirements for Pharmaceuticals for Human Use (ICH): Comparability of Biotechnological/Biological Products Subject to Changes in Their Manufacturing Process: Q5E. http://www.ich.org/fileadmin/ Public_Web_Site/ICH_Products/Guidelines/Quality/Q5E/Step4/ Q5E_Guide line.pdf. Accessed 21 Jan 2021.

2. European Medicines Agency. Guideline on Similar Biological Medicinal Products, CHMP/437/04 Rev 1. https://www.ema. europa.eu/en/documents/scientific-guideline/guideline-simil ar-biological-medicinal-products-rev1_en.pdf. Accessed 21 Jan 2021.

3. US Food and Drug Administration. Biosimilars: Questions and Answers Regarding Implementation of the Biologics Price Competition and Innovation Act of 2009: Guidance for Industry. http:// www.fda.gov/downloads/Drugs/GuidanceComplianceRegulat oryInformation/Guidances/UCM444661.pdf. Accessed 21 Jan 2021.

4. Declerck P, Mourad FR, Rudd PM. Biosimilarity versus manufacturing change: two distinct concepts. Pharm Res. 2016;33:261-8. https://doi.org/10.1007/s11095-015-1790-3. Accessed 7 February 2021.

5. Jefferis R. Biologics: structural heterogeneity and immunogenicity. Br Jo Hosp Medi. 2017. https://doi.org/10.12968/hmed.2017. 78.8.443. Accessed 7 February 2021.

6. Vlasak J, Ionescu R. Heterogeneity of monoclonal antibodies revealed by charge-sensitive methods. Curr Pharm Biotechnol. 
2008;9:468-81. https://doi.org/10.2174/138920108786786402. Accessed 10 March 2021.

7. Webster CJ, Wong A, Woollett GR. An efficient development paradigm for biosimilars. BioDrugs. 2019. https://doi.org/10.1007/ s40259-019-00371-4. Accessed 7 February 2021.

8. Vezer B, Buzas Z, Sebeszta M, Zrubka Z. Authorized manufacturing changes for therapeutic monoclonal antibodies (mAbs) in European Public Assessment Report (EPAR) documents. Curr Med Res Opin. 2016. https://doi.org/10.1185/03007995.2016. 1145579. Accessed 21 January 2021.

9. US Food and Drug Administration. Guidance for Industry: Scientific Considerations in Demonstrating Biosimilarity to a Reference Product. 2015. https://www.fda.gov/media/82647/download. Accessed 21 Jan 2021.

10. Berkowitz SA, Engen JR, Mazzeo JR, Jones GB. Analytical tools for characterizing biopharmaceuticals and the implications for biosimilars. Nat Rev Drug Discov. 2021;2012(11):527-40. https:// doi.org/10.1038/nrd3746. Accessed 7 February 2021.

11. Medicines and Healthcare products Regulatory Agency (United Kingdom). MHRA guidance on the licensing of biosimilar products. 2020. https://www.gov.uk/government/consultations/mhradraft-guidance-on-the-licensing-of-biosimilar-products/consu ltation-document-mhra-guidance-on-the-licensing-of-biosimilarproducts. Accessed 2 Mar 2021.

12. Bielsky MC, Cook A, Wallington A, Exley A, Kauser S, Hay JL, Both L, Brown D. Streamlined approval of biosimilars: moving on from the confirmatory efficacy trial. Drug Discov Today. 2020. https://doi.org/10.1016/j.drudis.2020.09.006. Accessed 2 March 2021.

13. Wolff-Holz E, Tiitso K, Vleminckx C, Weise M. Evolution of the EU biosimilar framework: past and future. BioDrugs. 2019. https://doi.org/10.1007/s40259-019-00377-y. Accessed 21 January 2021.

14. National Academies of Sciences, Engineering, and Medicine 2020. Regulating Medicines in a Globalized World: The Need for Increased Reliance Among Regulators. Washington, DC: The National Academies Press. https://doi.org/10.17226/25594. Accessed 2 March 2021.

15. US Food and Drug Administration. Demonstration of Comparability of Human Biological Products, Including Therapeutic Biotechnology-derived Products, April 1996. https://www.fda. gov/drugs/guidancecomplianceregulatoryinformation/guidances/ ucm122879.htm. Accessed 2 Mar 2021.

16. European Medicines Agency. Concept Paper on the Development of a Committee for Proprietary Medicinal Products (CPMP) Guideline on Comparability of Biotechnology-Derived Products, CPMP/BWP/1113/98. 1998. https://www.ema.europa.eu/en/ documents/scientific-guideline/concept-paper-developmentcommittee-proprietary-medicinal-products-cpmp-guidelinecomparability_en.pdf. Accessed 21 Jan 2021.

17. European Medicines Agency. Guideline on comparability of medicinal products containing biotechnology-derived proteins as active substance - quality issues (revision 1). EMA/CHMP/ BWP/247713/2012 May 2014. https://www.ema.europa.eu/en/ documents/scientific-guideline/guideline-similar-biological-medic inal-products-containing-biotechnology-derived-proteins-active_ en-0.pdf. Accessed 7 Feb 2021

18. European Medicines Agency. Guideline on comparability of medicinal products containing biotechnology-derived proteins as active substance: non-clinical and clinical issues. EMEA/ CPMP/3097/02/Final. 2003. https://www.ema.europa.eu/en/ documents/scientific-guideline/guideline-comparability-medic inal-products-containing-biotechnology-derived-proteins-active/ bmwp/101695/06_en.pdf. Accessed 21 Jan 2021.

19. World Health Organization. Annex 2: Guidelines on evaluation of similar biotherapeutic products (SBPs). https://www.who.int/
biologicals/publications/trs/areas/biological_therapeutics/TRS_ 977_Annex_2.pdf. Accessed 7 Feb 2021.

20. Health Canada. Guidance Document: Information and Submission Requirements for Biosimilar Biologic Drugs. https://www. canada.ca/en/health-canada/services/drugs-health-products/biolo gics-radiopharmaceuticals-genetic-therapies/applications-submi ssions/guidance-documents/information-submission-requiremen ts-biosimilar-biologic-drugs-1.html. Accessed 7 Feb 2021.

21. Therapeutic Goods Administration (Australia). Biosimilar Medicines Regulation. https://www.tga.gov.au/sites/default/files/biosi milar-medicines-regulation.pdf. Accessed 7 Feb 2021.

22. Agência Nacional de Vigilância Sanitária -ANVISA (Brazil): Resolução da Diretoria Colegiada-RDC nº55, de 16 de Dezembro de 2010. http://antigo.anvisa.gov.br/documents/10181/27183 76/\%281\%29RDC_55_2010_COMP.pdf. Accessed 21 Jan 2021.

23. Lamanna WC, Holzmann J, Cohen HP, Guo X, Schweigler M, Stangler T, Seidl A, Schiestl M. Maintaining consistent quality and clinical performance of biopharmaceuticals. Expert Opin Biol Ther. 2021;2018(18):369-79. https://doi.org/10.1080/14712598. 2018.1421169. Accessed 2 March 2021.

24. Walsh G, Jefferis R. Post-translational modifications in the context of therapeutic proteins. Nat Biotechnol. 2006;24:241-1252. https://doi.org/10.1038/nbt1252.. Accessed 7 February 2021.

25. Zhuang Y, Chen D, Sharma A, Xu Z. Risk-based comparability assessment for monoclonal antibodies during drug development: a clinical pharmacology perspective. AAPS J. 2018;20:109-22. https://doi.org/10.1208/s12248-018-0268-8. Accessed 7 February 2021.

26. Vandekerckhove K, Seidl A, Gutka H, Kumar M, Gratzl G, Keire D, Coffey T, Kuehne H. Rational selection, criticality assessment, and tiering of quality attributes and test methods for analytical similarity evaluation of biosimilars. AAPS J. 2018. https://doi. org/10.1208/s12248-018-0230-9. Accessed 2 March 2021.

27. European Medicines Agency. Reflection paper on statistical methodology for the comparative assessment of quality attributes in drug development, EMA/CHMP/138502/2017. https://www.ema. europa.eu/en/documents/scientific-guideline/draft-reflectionpaper-statistical-methodology-comparative-assessment-qualityattributes-drug_en.pdf. Accessed 21 Jan 2021.

28. van der Plas RM, Hoefnagel MHN, Hillege HL, Roes KCB. Pragmatic rules for comparability of biological medicinal products. Biologicals. 2019. https://doi.org/10.1016/j.biologicals.2019.11. 002. Accessed 2 March 2021.

29. Creamer JS, Oborny NJ, Lunte SM. Recent advances in the analysis of therapeutic proteins by capillary and microchip electrophoresis. Anal Methods. 2021;2014(15):5427-49. https://doi.org/10. 1039/C4AY00447G. Accessed 15 March 2021.

30. Rathore D, Faustino A, Schiel J, Pang E, Boyne M, Rogstad S. The role of mass spectrometry in the characterization of biologic protein products. Expert Rev Proteom. 2021;2018(15):431-49. https://doi.org/10.1080/14789450.2018.1469982. Accessed 15 March 2021

31. Brinson RG, et al. Enabling adoption of 2D-NMR for the higher order structure assessment of monoclonal antibody therapeutics. MAbs. 2018. https://doi.org/10.1080/19420862.2018.1544454. Accessed 21 January 2021.

32. Lamanna WC, Mayer RE, Rupprecther A, Fuchs M, Higel F, Fritsch C, Vogelsang C, Seidl A, Toll H, Schiestl M, Holzmann J. The structure-function relationship of disulfide bonds in etanercept. Science Rep. 2017;7: 3951. https://www.nature.com/artic les/s41598-017-04320-5. Accessed 21 Jan 2021.

33. Ghasriani H, Hodgson DJ, Brinson RG, McEwen I, Buhse LF, Kozlowski S, Marino JP, Aubin Y, Keire DA. Precision and robustness of 2D-NMR for structure assessment of filgrastim biosimilars. Nat Biotechnol. 2016; 34: 139-41. https://www.nature. com/articles/nbt.3474. Accessed 15 Mar 2021. 
34. Schiestl M, Stangler T, Torella C, Cepeljnik T, Toll H, Grau R. Acceptable changes in quality attributes of glycosylated biopharmaceuticals. Nat Biotechnol. 2021;2011(29):310-2. https://doi. org/10.1007/s40259-020-00422-1. Accessed 19 March 2021.

35. Higel H, Seidl A, Sörgel F, Friess W. N-glycosylation heterogeneity and the influence on structure, function and pharmacokinetics of monoclonal antibodies and $\mathrm{Fc}$ fusion proteins. Eur J Pharm Biopharm. 2021;2016(100):94-100. https://doi.org/10.1016/j. ejpb.2016.01.005. Accessed 15 March 2021.

36. Kim S, Song J, Park S, Ham S, Paek K, Kang M, Chae Y, Seo H, $\mathrm{Kim} \mathrm{H}-\mathrm{C}$, Flores M. Drifts in ADCC-related quality attributes of Herceptin: Impact on development of a trastuzumab biosimilar. MAbs. 2017. https://doi.org/10.1080/19420862.2017.1305530. Accessed 15 March 2021

37. Jae HL, Paek K, Moon JH, Ham S, Song J, Kim S. Biological Characterization of SB3, a trastuzumab biosimilar, and the influence of changes in reference product characteristics on the similarity assessment. BioDrugs. 2019. https://doi.org/10.1007/s40259019-00362-5. Accessed 15 March 2021.

38. US Food and Drug Administration. Draft guidance for industry: comparability protocols for human drugs and biologics: chemistry, manufacturing, and controls information. Revision 1, 2016. https://www.fda.gov/media/97148/download. Accessed 6 Mar 2021.

39. European Medicines Agency. Guideline on non-clinical and clinical development of similar biological medicinal products containing recombinant erythropoietins. EMEA/ CHMP/ BMWP/301636/2008 Rev. 2018. https://www.ema.europa.eu/en/ documents/scientific-guideline/guideline-non-clinical-clinicaldevelopment-similar-biological-medicinal-products-containing en-1.pdf. Accessed 15 Mar 2021

40. European Medicines Agency. Guideline on similar biological medicinal products containing monoclonal antibodies-nonclinical and clinical issues. EMA/CHMP/ BMWP/403543/2010 May 2012. https://www.ema.europa.eu/en/documents/scientificguideline/guideline-similar-biological-medicinal-products-conta ining-monoclonal-antibodies-non-clinical_en.pdf. Accessed 15 Mar 2021.

41. European Medicines Agency. Guidance on Similar Medicinal Products Containing Recombinant Granulocyte-Colony Stimulating Factor. EMEA/CHMP/BMWP/ 31329/2005. 2006. https:// www.ema.europa.eu/en/documents/scientific-guideline/annexguideline-similar-biological-medicinal-products-containing-biote chnology-derived-proteins_en.pdf. Accessed 15 Mar 2021.

42. European Medicines Agency. Guideline on the Investigation of Bioequivalence, 2010. CPMP/EWP/QWP/1401/98 Rev. 1/Corr. https://www.ema.europa.eu/en/documents/scientific-guideline/ guideline-investigation-bioequivalence-rev1_en.pdf. Accessed 21 Jan 2021

43. US Food and Drug Administration. Guidance for Industry: Clinical Pharmacology Data to Support a Demonstration of Biosimilarity to a Reference Product. 2016. https://www.fda.gov/media/ 88622/download. Accessed 6 Mar 2021.

44. Schiestl M, Ranganna G, Watson K, Jung B, Roth K, Capsius B, Trieb M, Bias P, Marechal-Jamil J. The path towards a tailored clinical biosimilar development. BioDrugs. 2020. https://doi.org/ 10.1007/s40259-020-00422-1. Accessed 2 March 2021.
45. Tu C-L, Wang Y-L, Hu T-M, Hsu L-F. Analysis of pharmacokinetic and pharmacodynamic parameters in EU versus US-licensed reference biological products: are in vivo bridging studies justified for biosimilar development? BioDrugs. 2019. https://doi.org/10. 1007/s40259-019-00357-2. Accessed 5 March 2021.

46. US Food and Drug Administration. Division of Pulmonary, Allergy and Rheumatology Products (DPARP) sBLA 125057/394 Humira $^{\mathrm{TM}}$ (adalimumab). Summary review for regulatory action. https://www.accessdata.fda.gov/drugsatfda_docs/nda/2015/12505 7Orig1s394SumR.pdf. Accessed 28 Mar 2021.

47. De Meulemeester J, Fedyk M, Jurkovica L, Reaume M, Dowlatshahi D, Stotts G, Shamy M. Many randomized clinical trials may not be justified: a cross-sectional analysis of the ethics and science of randomized clinical trials. J Clin Epidemiol. 2021;2018(97):20-5. https://doi.org/10.1016/j.jclinepi.2017.12. 026.Accessed12February.

48. International Council for Harmonisation of Technical Requirements for Pharmaceuticals for Human Use (ICH): General Considerations for Clinical Trials E8. 1997. https://database.ich.org/ sites/default/files/E8_Guideline.pdf. Accessed 22 Mar 2021.

49. US Food and Drug Administration: Guidance for Industry: INDs for Phase 2 and Phase 3 Studies - Chemistry, Manufacturing, and Controls Information, 2003. https://www.fda.gov/media/70822/ download. Accessed 22 Mar 2021.

50. Webster CJ, Woollett GR. A 'global reference' comparator for biosimilar development. BioDrugs. 2017. https://doi.org/10.1007/ s40259-017-0227-4. Accessed 11 March 2021.

51. World Health Organization. WHO Guidelines on submission of documentation for the pilot procedure for prequalification of similar biotherapeutic products for rituximab and trastuzumab. 2020. https://www.who.int/medicines/regulation/02_Pilot_PQ_antic ancer_fullPathway_20Feb2020.pdf?ua=1. Accessed 7 Feb 2021.

52. Rifkin R, Pourmahram T. Biosimilars Bring Value to Health Care. 2020. https://www.centerforbiosimilars.com/view/biosimilarsbring-value-to-health-care. Accessed 16 June 2021.

53. Mulcahy AW, Hlavka JP, Case SR. Biosimilar cost savings in the United States: initial experience and future potential. Rand Health Q. 2018; 7: 3 https://www.ncbi.nlm.nih.gov/pmc/articles/PMC60 75809/. Accessed 26 Mar 2021.

54. Medicines for Europe. The Impact of Biosimilar Competition in Europe. May 2017. https://www.medicinesforeurope.com/wpcontent/uploads/2017/05/IMS-Biosimilar-2017_V9.pdf. Accessed 7 Feb 2021.

55. van Meer PJK, Ebbers HC, Kooijman M, Gispen-de Wied CC, Silva-Lima B, Moors EHM, Schellekens H. Contribution of animal studies to evaluate the similarity of biosimilars to reference products. Drug Discov Today. 2021;2015(20):483-90. https://doi. org/10.1016/j.drudis.2014.11.009. Accessed 7 Feb 2021 